\title{
Morfologia do seio coronário em fetos de bovinos azebuados
}

\author{
Morphology of coronary sinus in bovine fetal hearts
}

\author{
Bruno Cesar SCHIMMING ${ }^{1}$; Raquel Fantin DOMENICONI ${ }^{1}$; José Carlos de ARAÚJO²; Antonio \\ Marcos ORSI ${ }^{1,3}$
}

\author{
${ }^{1}$ Departamento de Anatomia do Instituto de Biociências da Universidade Estadual Paulista, Botucatu, SP, Brasil \\ ${ }^{2}$ Departamento de Anatomia do Centro de Ciências Biológicas da Universidade Estadual de Londrina, Londrina, PR, Brasil \\ ${ }^{3}$ Faculdade de Medicina e Enfermagem da Universidade de Marília, Marília, SP, Brasil
}

\begin{abstract}
Resumo
O seio coronário em fetos de bovinos azebuados é estudado através de dissecções e radiografias vasculares. Há dois padrões predominantes de formação: por continuação direta da veia ázigos esquerda, a partir da veia cardíaca magna; e pela união da veia cardíaca magna com a veia ázigos esquerda. O primeiro padrão de formação do seio coronário apareceu em 17 animais, enquanto o segundo padrão foi encontrado em 13 animais. Quanto ao sexo, não houve diferença entre os padrões apresentados. Os principais tributários venosos do seio coronário em fetos de bovinos são representados pelos seguintes vasos: veia cardíaca magna, veia cardíaca média, veias da face atrial do ventrículo esquerdo e, veias oblíquas do átrio esquerdo. A veia cardíaca magna é observada como uma continuação direta da veia interventricular paraconal. A partir destes resultados, constata-se que o padrão venoso cardíaco no feto bovino é predominantemente confluente ao seio coronário. Apenas um pequeno número de vasos é diretamente confluente ao átrio direito do coração bovino.
\end{abstract}

Palavras-chave: Coração. Veias cardíacas. Anatomia. Bovinos.

\begin{abstract}
The coronary sinusin fetuses ofzebu-crossedbovinesis studiedbyvasculardissectionsand radiographs. There aretwopredominant patterns offormation of thecoronary sinus: bydirect continuation of theleft azygos vein, from thegreat cardiac vein, and by theunion of thegreat cardiac veinwith theleft azygos vein. The first patternappeared in17animals, while thesecondpatternformation of thecoronary sinuswas found in13animals. Regarding sex there was nodifference between thepatterns shown. The main tributariesof the coronaryveinincattleare representedby the followingvessels: great cardiac vein, middle cardiac vein, veins of the faceof theleft ventricle andatrium, obliqueveinof left atrium. The great cardiac veinisseen asadirect continuation of theinterventricular veinparaconal. From these results, it appears thatthe standardvenousfetalbovineheartis predominantlyconfluentthe coronary sinus. Onlyasmall number ofvesselsare directlyconfluentto theright atrium ofbovine heart.
\end{abstract}

Keywords: Heart. Cardiacvein. Anatomy. Bovine.

\section{Introdução}

O sistema de drenagem venosa em corações de mamíferos domésticos apresenta-se como um importante campo de investigação científica, pois os bovinos azebuados são animais de importância econômica e de interesse zootécnico e científico para o Brasil. Segundo Bossi, Caradonna e Spampani ${ }^{1}$, o seio coronário deve ser distinto da veia cardíaca magna, por representar um remanescente da veia cava cranialesquerda, existente no embrião. Em equinos, cães e cobaias, alguns autores consideram o seio coronário como sendo um prolongamento do ramo circunflexo da veia cardíaca magna e, afirmam que este desemboca diretamente no átrio direito ${ }^{2,3,4}$.

Normalmente, o seio coronário é a principal estrutura anatômica de término da drenagem venosa do coração em animais domésticos, porém, há relatos que citam a ausência do seio coronário em animais

Correspondência para:

Bruno Cesar Schimming

Departamento de Anatomia, Instituto de Biociências de Botucatu, UNESP

Cx. Postal, 510, Distrito de Rubião Júnior, , Botucatu, SP, Brasil.

CEP:18618-970

e-mail: bruno@ibb.unesp.br

Recebido: 11/01/2012

Aprovado: 31/10/2012 
como equinos e búfalos ${ }^{5,6}$. Neste caso, os autores destacam a importância da veia ázigos esquerda, que drena o sangue das principais veias cardíacas ao átrio direito, considerando esta veia como substituta do seio coronário.

A válvula do seio coronário relatada em humanos $^{7}$ também pode ocorrer em animais domésticos, podendo nestes, ser constante ou não. Há descrições desta válvula no cavalo, boi, carneiro, porco e cão ${ }^{8}$. Há controvérsias entre a presença ou não desta válvula em ruminantes. Há descrições de uma pequena válvula semilunar ${ }^{9,10}$, assim, como há relatos de ausência valvular no seio coronário em ruminantes ${ }^{11}$.

A veia cava cranial esquerda, em bovinos, desaparece no decorrer do desenvolvimento embrionário, porém, sua porção terminal persiste como a parte cefálica da veia cardinal posterior esquerda, resultando na formação da veia ázigos esquerda ${ }^{12}$. O seio coronário pode ter a sua origem a partir da união da veia ázigos esquerda com a veia cardíaca magna. Esta origem foi observada em carnívoros ${ }^{13}$, ruminantes ${ }^{9,11}$ e suínos ${ }^{9,14}$. O seio coronário também pode ter sua origem a partir da veia ázigos esquerda e desembocar no átrio direito ${ }^{15}$.

Com base nas informações apresentadas, esta pesquisa teve como objetivo caracterizar a morfologia anatômica do seio coronário em fetos de bovinos azebuados, tendo em vista, contribuir com o conhecimento morfológico desta espécie de elevada importância zootécnica e econômica.

\section{Material e Método}

Neste trabalho, foram utilizados corações de 30 fetos a termo de bovinos azebuados, provenientes de frigoríficos abatedouros do estado de São Paulo. Realizou-se incisão sagital mediana, do manúbrio à cartilagem xifóide do esterno, rebateu-se a pele, a tela subcutânea e os músculos da parede torácica. A seguir, foi feita uma esternotomia longitudinal e a colocação de afastadores, para acessar o mediastino médio. O pericárdio, então, foi aberto, por incisão longitudinal, o coração foi tracionado e os vasos da base foram seccionados e o órgão removido. Uma vez isolado, os corações foram lavados em água corrente. Neste momento, fez-se repetidamente suaves massagens a partir do ápice cardíaco em direção à base do coração, com o objetivo de esvaziar o conteúdo sanguíneo o máximo possível. Os corações foram identificados e separados em dois grupos de 15 corações, entre machos e fêmeas. Todos os corações tiveram o sistema venoso cardíaco injetado por meio de uma cânula introduzida no seio coronário, após abertura do átrio direito. Este foi injetado com uma solução de 50\% de Neoprene Látex $650^{\circ}$ (Dupont do Brasil S.A. Ind. Quím., Rio de Janeiro, Brasil) e 50\% de Celobar (Laboratório Maurício Villela, Rio de Janeiro, Brasil). A solução foi corada e diluída, para atingir o nível capilar, porém foi suficientemente espessa para não atravessá-lo, permitindo assim, o preenchimento dos vasos mais finos. Posteriormente, estes corações foram radiografados e fixados em solução aquosa de formaldeído a 10\%, durante no mínimo, 48 horas. Realizou-se então, a dissecção macroscópica e mesoscópica, individualizando os componentes venosos dos corações bovinos.

Com o auxílio de um paquímetro, foram realizadas mensurações no comprimento do seio coronário nos corações fixados, considerando geralmente o seu início na confluência da veia ázigos esquerda com a veia cardíaca magna e o seu término no átrio direito. Mediu-se também o comprimento do coração, dividindo-o em duas submedidas: (1) comprimento total, da base (região entre as veias pulmonares) até o ápice cardíaco; (2) comprimento parcial (sulco coronário ao ápice cardíaco). A largura do coração foi estabelecida na região do sulco atrioventricular. Todas as medidas foram expressas em centímetros $(\mathrm{cm})$. Além disso, os corações foram pesados em uma balança de precisão 
(Micronal',São Paulo, Brasil) e o peso foi expresso em gramas $(\mathrm{g})$.

Os corações dissecados e radiografados foram fotografados e o sistema de drenagem venosa cardíaca encontrado nos corações foi esquematizado. Usou-se a nomenclatura de acordo com o International Commiteeon Veterinary Gross Anatomical Nomenclature ${ }^{16}$.

\section{Resultados}

O seio coronário de fetos bovinos azebuados é formado a partir de dois padrões de constituição anatômica. O primeiro descreve o seio coronário sendo contínuo da veia ázigos esquerda a partir da veia cardíaca magna, o que foi encontrado em 56,66\% dos corações (17 corações, sendo oito de machos e nove de fêmeas) (Figura 1). O outro padrão encontrado reporta a formação do seio coronário a partir da união da veia cardíaca magna com a veia ázigos esquerda, $o$ que foi observado em 43,34\% dos corações (13 corações, sendo sete de machos e seis de fêmeas) (Figura 2). Não havendo diferenças ente os padrões e nem entre os sexos.

As principais tributárias venosas do seio coronário do coração de fetos bovinos são as veias cardíaca magna e média, da face atrial do ventrículo esquerdo e oblíquas do átrio esquerdo (Figura 1). A veia cardíaca magna em todos os corações estudados é uma continuação direta da veia interventricular paraconal (Figura 3). Esta veia pode confluir diretamente ao seio coronário (17 animais) ou unir-se à veia ázigos esquerda e, assim, formarem o seio coronário (13 animais). A veia cardíaca média cursa na face atrial do coração em sintopia com o ramo descendente subsinuoso da artéria coronária direita, confluindo diretamente ao seio coronário em $96,66 \%$ dos corações (29 corações, sendo 14 de machos e 15 de fêmeas) (Figura 2). Em apenas um coração, de um animal macho, foi observada a confluência direta desta veia ao átrio direito.

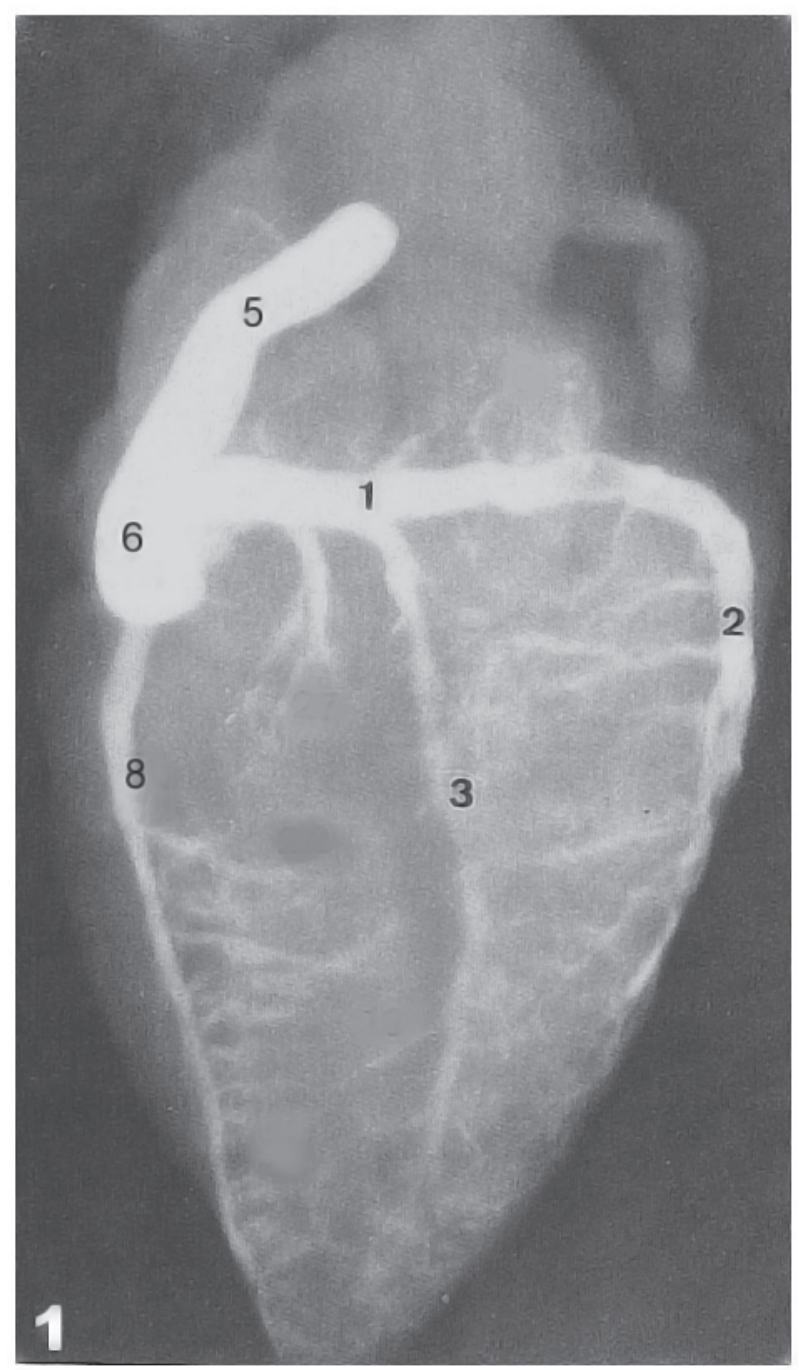

Figura 1- Radiografia do coração de feto bovino. São indicados (1) veia cardíaca magna, (2) veia interventricular paraconal, (3) veia cardíaca caudal, (5) veia ázigos esquerda, (6) seio coronário e (8) veia cardíaca média

As observações sobre o peso dos corações e mensurações do comprimento total e parcial, largura do coração e comprimento dos seios coronários, feitas nos 30 corações de fetos de bovinos azebuados, são apresentadas na tabela 1. A análise comparativa destes parâmetros em relação ao fator geral de variação sexo não mostra diferenças significantes.

\section{Discussão}

O seio coronário, situado na face atrial do coração, drena o sangue da veia ázigos esquerda e desemboca 


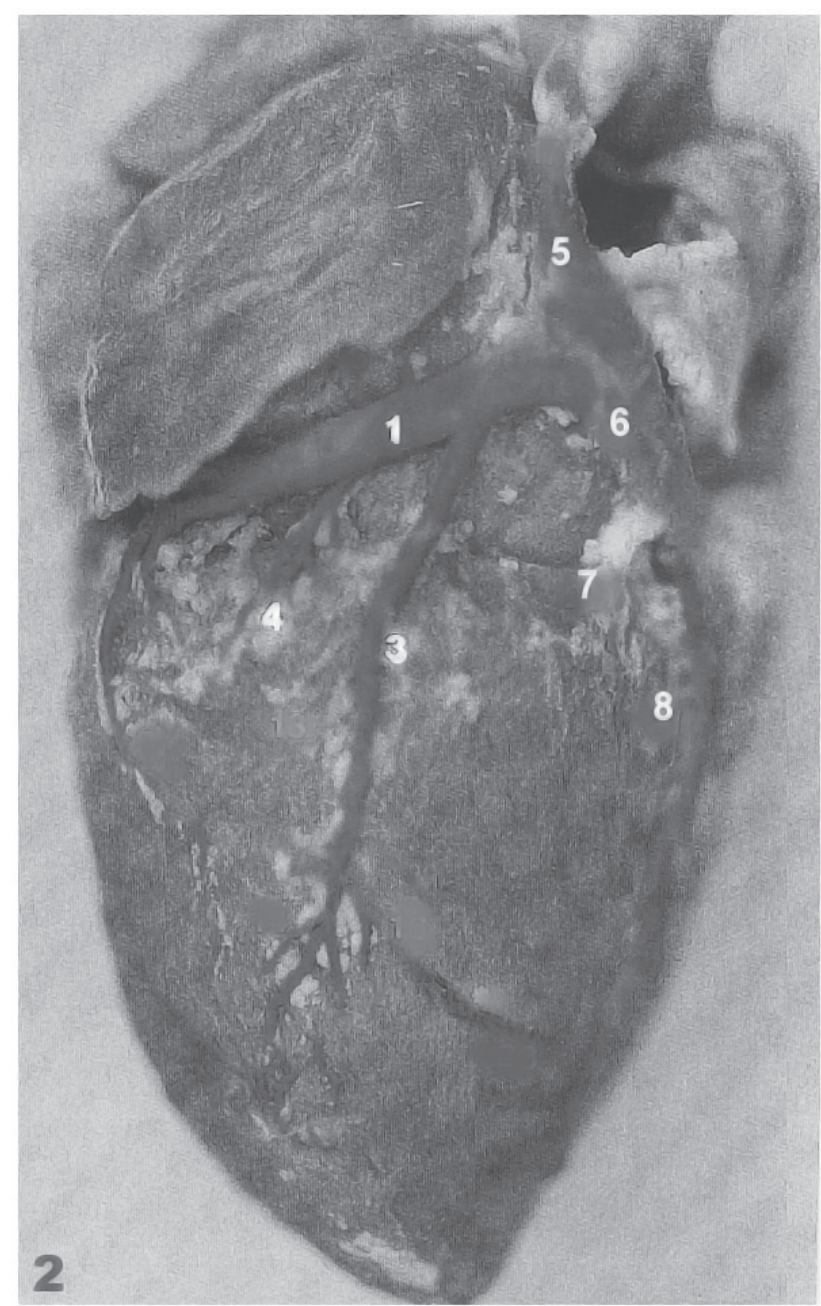

Figura 2 - Fotografia do coração de feto bovino. Observamse (1) veia cardíaca magna, (3) veia cardíaca caudal, (4) veia marginal do ventrículo esquerdo, (5) veia ázigos esquerda, (6) seio coronário, (7) veias da face atrial do ventrículo esquerdo e (8) veia cardíaca média

Tabela 1 - Média dos dados morfométricos dos corações de fetos bovinos azebuados - Botucatu - 2012

\begin{tabular}{ccc}
\hline mensurações & machos & fêmeas \\
\hline peso médio coração $(\mathrm{g})$ & 85,78 & 83,65 \\
comprimento total coração $(\mathrm{cm})$ & 7,99 & 7,89 \\
comprimento parcial coração $(\mathrm{cm})$ & 5,76 & 5,50 \\
largura média coração $(\mathrm{cm})$ & 4,93 & 4,78 \\
comprimento seio coronário $(\mathrm{cm})$ & 2.02 & 1,81 \\
\hline
\end{tabular}

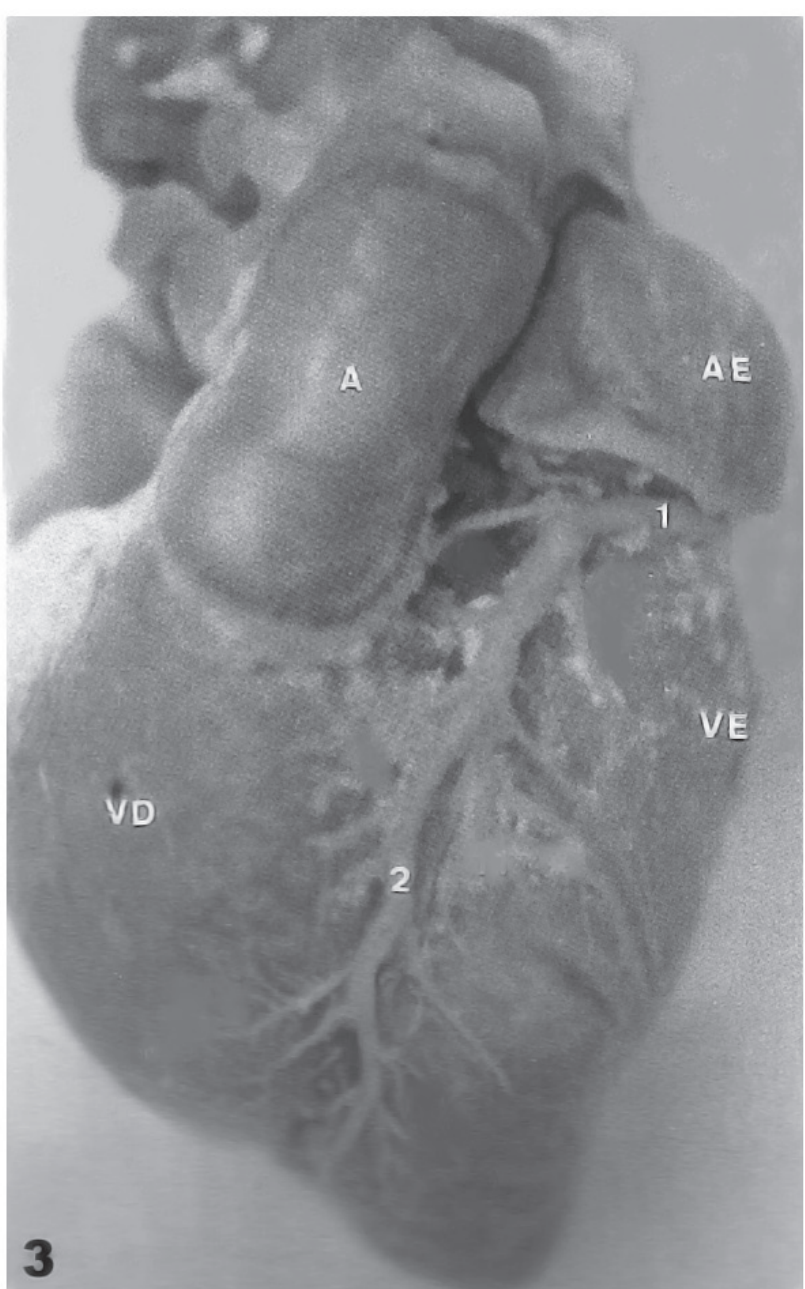

Figura 3 - Fotografia do coração de feto bovino azebuado. Observam-se (1) veia cardíaca magna, (2) veia interventricular paraconal, (A) tronco pulmonar, (AE) átrio esquerdo, (VE) ventrículo esquerdo e (VD) ventrículo direito

no átrio direito ${ }^{17}$. Quanto à formação do seio coronário no coração de fetos de bovinos azebuados, observamos que o mesmo pode ter uma constituição dual: é a continuação direta da veia ázigos esquerda, a partir da veia cardíaca magna ou é a união da veia cardíaca magna com a veia ázigos esquerda. Para Moreira et al. ${ }^{18}$, a veia ázigos é um componente constante do seio coronário em ovinos, recolhendo em seu trajeto afluentes atriais.

O primeiro padrão de formação do seio coronário encontrado em 17 corações de fetos bovinos (56,66\%), a partir da veia ázigos esquerda, encontra 
suporte, inclusive com base ontogenética; onde no decurso do desenvolvimento embrionário desaparece uma parte da veia cava cranial esquerda, persistindo a sua porção terminal como parte cefálica da veia cardinal posterior esquerda, o que resulta na formação da veia ázigos esquerda, que responde pela drenagem venosa de todo o sangue que vem do coração para o seio coronário, o que pode levar a inferir que o seio coronário resulta de um prolongamento daquela veia ${ }^{12,19}$. Segundo Besoluk e Tipirdamaz ${ }^{20}$, o seio coronário do coração em ovinos Akkaraman e caprinos Angorá pode ser considerado uma continuação da veia ázigos esquerda, o qual drena diretamente para o átrio direito e ventralmente ao óstio da veia cava caudal.

A formação do seio coronário a partir da união da veia cardíaca magna com a veia ázigos esquerda, encontrada neste estudo em 43,33\% dos corações, corrobora as descrições feitas para a formação do seio coronário em cães e gatos ${ }^{13}$, e ruminantes e suínos ${ }^{9,11,14}$.

A despeito das considerações anteriores, deve-se destacar que alguns autores consideram que o seio coronário é um prolongamento do ramo circunflexo da veia cardíaca magna ${ }^{2,3,4}$. Para Esperança Pina, Correia e O 'Neill ${ }^{21}$, em cães o seio coronário é a continuação direta da veia cardíaca magna. No entanto, no coração do equino, o seio coronário deve ser distinto da veia cardíaca magna, uma vez que ele representa um remanescente direto da veia cava cranial esquerda do embrião ${ }^{1}$.

Nos animais domésticos, geralmente, o seio coronário recebe o sangue venoso da veia cardíaca magna, veia cardíaca média e veia ázigos esquerda ${ }^{22}$. Em ovinos Akkaraman e caprinos Angorá, o sangue das veias cardíaca média e cardíaca magna drena para o seio coronário. Além destas veias, no caprino Angorá, a veia marginal esquerda também drena para o seio coronário $^{20}$. Em porcos-espinhos, as veias cardíaca magna e distal do ventrículo esquerdo se abrem no seio coronário ${ }^{23}$. Para estes autores, a veia distal do ventrículo esquerdo forma o limite entre o seio coronário e a veia cardíaca magna.

Em corações de fetos bovinos azebuados, verifica-se que os parâmetros mensurados, como peso médio dos corações, comprimento total e parcial, largura dos corações e comprimento do seio coronário são, em média, sempre maiores nos animais machos do que nas fêmeas. Nos animais domésticos, o peso cardíaco nos machos é frequentemente maior que o peso cardíaco nas fêmeas ${ }^{9,14,24}$. Evidentemente, o comprimento cardíaco do sulco coronário ao ápice cardíaco e da largura na base cardíaca, com valores médios de 17 e $12 \mathrm{~cm}$, respectivamente, encontrados em corações bovinos adultos ${ }^{10}$, são maiores aos achados neste estudo (comprimento parcial de 5,76 $\mathrm{cm}$ e largura de $4,93 \mathrm{~cm}$, nos animais machos), já que são oriundos de corações de fetos bovinos.

O comprimento do seio coronário de fetos bovinos apresentou valores médios entre $2,02 \mathrm{~cm}$ para os machos e 1,88 $\mathrm{cm}$ para as fêmeas. Besoluk e Tipirdamaz ${ }^{20}$ citam valores de 2,5 e 2,8 cm para o comprimento deste seio em ovinos e caprinos adultos, respectivamente.

Com base nos nossos resultados, constata-se que o padrão venoso cardíaco no feto bovino é predominantemente confluente ao seio coronário. As características morfológicas do seio coronário, encontradas em corações de fetos bovinos azebuados, mostraram dois padrões de origem, como uma continuação direta da veia ázigos esquerda, a partir da veia cardíaca magna e, pela união da veia cardíaca magna com a veia ázigos esquerda, o que quando comparado aos relatos anteriores para outros animais domésticos, não mostra diferenças significativas. 


\section{Referências}

1. BOSSI, V.; CARADONNA, G. B.; SPAMPANI, G. Trattato di anatomia veterinaria. Milano: F. Vallardi, 1909. p. 274-275.

2. BRADLEY, O. C. The topographical anatomy of the thorax and abdomen of the horse. Edinburgh: W. Green, 1922. p. 28-29.

3. BRADLEY, O. C.; GRAHAME, T. Topographical anatomy of the dog. 5. ed. London: Oliver and Boyd, 1948. p. 60-61.

4. LOPES DE FREITAS, E. F.; ORSI, A. M.; VICENTINI, C. A. Sobre a drenagem venosa do coração da cobaia (Caviaporcellus, L.). Revista de Ciência Biomédica, v. 10, p. 85-89, 1989.

5. SCHMALTZ, R. Atlas der anatomie des pferdes. Berlin: R. Schoetz, 1927. p. 79-81.

6. LEMBO, C. M. Studies on the cardiac venous circulation in the buffalo. Quaderno di Anatomia Pratica, v. 24, p. 69-82, 1968.

7. GARDNER, E.; GRAY, D. J.; O'RAHILLY, R. Anatomia. Estudo regional do corpo humano. 4. ed. Rio de Janeiro: Guanabara-Koogan, 1988. p. 312.

8. BERTHO, E. The normal comparative anatomy of the arteries and veins of the heart in different species of animals. Archivos Anatomia Histologia Embryologia, v. 1, p. 283-309, 1964.

9. SCHWARZE, E.; SCHRÖDER, L. Compedio de anatomia veterinária. Zaragoza: Acribia, 1972, v. 3, p. 14-97.

10. GOSHAL, N. G. Coração e artérias de equino. In: GETTY, R. Sisson/Grosmann. Anatomia dos animais domésticos. 6. ed. Rio de Janeiro: Guanabara-Koogan, 1986. v. 1, p. 518-530.

11.GODINHO, H. P.; CARDOSO, F. M.; NASCIMENTO, J. F. Anatomia dos animais domésticos. Belo Horizonte: Instituto de Ciências Biológicas da UFMG, 1981. p. 338-339.

12. BARONE, R.; MALAVIELLE, R. Lesveinesducoeur chezlesmamiferes. C. R. Association del'anatomie, v. 43, p. 199-217, 1957.

13. CHRISTENSEN, G. C.; CAMPETI, F. L. Anatomic and functional studies of the coronary circulation in the dog and pig. American Journal of Veterinary Research, v. 20, p. 18-26, 1959.

14. QUEIROZ, S. Morfologia e morfometria do seio coronário de suínos (Sus scrofa domestica, L. 1765). Revista Brasileira de Ciência Morfológica, v. 7, n. 1, p. 51-54, 1990.

15.HEGAZI, A. H. Die blutgefabuersorgung des Herzens von rind, schaf und ziege. Zentralblatt fur Veterinarmedizin, v. 5, p. 776-819, 1958.

16. INTERNATIONAL COMMITTEE ON VETERINARY GROSS ANATOMICAL NOMENCLATURE. Nomina Anatomica Veterinaria. 5. ed. Hannover: International Committee on Veterinary Gross Anatomical Nomenclature, 2005. 166 p. Disponível em: <http://www.wava-amav.org/dowloads/ nav_2005.pdf >. Acessoem: 13 dez. 2011.

17. COAKLEY, J. B.; SUMMERFIELD, K. T. Cardiac muscle relations of the coronary sinus, the oblique vein of the left atria and the left precaval vein in mammals. Journal of Anatomy, v. 93, pt. 1, p. 30-35, 1993.

18.MOREIRA, P. R. R.; ANTÔNIO, T. S.; SOUZA, W. M.; SOUZA, N. T. M.; CORRÊA, C. N. Afluentes ventriculares e atriais do seio coronário no ovino (Ovis Áries - Linnaeus, 1758). ArsVeterinaria, v. 23, n. 1, p. 1-7, 2007.

19. GETTY, R. Sisson/Grossman Anatomia dos animais domésticos. 5. ed. Rio de Janeiro: Guanabara-Koogan,1991. p. 900-940.

20.BESOLUK, K.; TIPIRDAMAZ, S. Comparative macroanatomic investigations of the venous drainage of the heart in akkaraman sheep and angora goats. Anatomia, Histologia, Embryologia, v. 30, n. 4 , p. 249-252, 2001.

21.ESPERANÇA PINA, J. A.; CORREIA, M.; O’NEILL, J. C. Morphology of the veins draining the coronary sinus to the dog. ActaAnatomica, v. 109, n. 2, p. 122-128, 1981.

22.NICKEL, R.; SCHUMMER, A.; SEIFERLE, E. The anatomy of the domestic animals. Berlin: P. Parey, 1981. v. 3, p. 54-63.

23.ATALAR, O.; YILMAZ, S.; DINÇ, G.; OZDEMIR, D. The venous drainage of the heart in porcupines (Hystrixcristata). Anatomia, Histologia, Embryologia, v. 33, p. 233-235, 2004.

24.EVANS, H. E. Miller's Anatomy of the dog. 3. ed. Philadelphia: Saunders Company, 1993. p. 586-601. 